\title{
What does it take? Getting Freshmen to Read the Material Before Class
}

\section{Dr. Fethiye Ozis, Northern Arizona University}

Fethiye started teaching in Civil and Environmental Engineering at Northern Arizona University in 2014. She has received her Ph.D. in environmental engineering from University of Southern California in 2005. Her doctorate work focused on modeling of bio filters for air pollution control. After graduation, she has been involved in K-12 STEM institutions both as a teacher and administrator. Her research interests include biotechnology for environmental issues, engineering education and initiatives that facilitate success of minority students in STEM fields.

Dr. Meliksah Demir, Northern Arizona University 


\title{
What does it take? Getting Engineering Freshmen to read the material before class
}

\begin{abstract}
:
Introduction to Environmental Engineering is a freshmen level introductory course that focuses on the Discourse of Environmental Engineering. For every class, the students learn new vocabulary, keep up with the course pace, and incorporate the terminology into their assignments. The students' struggle with the new language becomes more pronounced when they do not complete the assigned readings prior to class. "Reading to learn" remains to be one of the biggest challenges college students face in their first year, especially when we take nation-wide reading levels into consideration (US Department of Education, NAEP, 2015). In Fall 2015, a "Mind Dump" pedagogical strategy was implemented to encourage students to read the class material for pre-exposure. The students have 4 minutes and 33 seconds of silence in class to write down everything they can remember from their reading (Whitman, 2015). Mind Dumps are used as cheat sheets during exams. The same procedure with the addition of guided reading questions were adapted for the Spring 2016 semester. Aggregated survey results from the first two semesters $(\mathrm{N} 1=78, \mathrm{~N} 2=75)$ showed that about one third of the students Agreed/Strongly Agreed with the statement "Mind Dumps make me complete my readings" one third was neutral and one third Disagreed/Strongly Disagreed with that statement. A new method, Classroom Preparation Assignment (CPA) was adopted in Fall 2016 for the third cohort (N3=94). The students answered guided reading questions for the CPA and brought two copies to the class where one was collected at the beginning of the class, and the second was kept to take notes on during class. The CPA becomes a study guide for course assessments. This study compared CPAs against Mind Dumps in their effectiveness to encourage the first year Civil and Environmental Engineering students to read assigned material prior to the lecture. Class Preparation Assignments (CPAs) was the most effective technique to get students to read the material prior to the class. The study also looked at the differences between the three cohorts for their engagement and learning as associated with their reading. Interestingly, groups did not differ from each other on engagement and learning. Although engagement was a reliable predictor of learning in every group, reading the material made the biggest contribution to learning in third cohort.
\end{abstract}

\section{Introduction:}

Many students come into the engineering program believing that they are good at math and science, so they should be a good fit for engineering as well. As Moran (2016) mentioned "engineering is no more applied Mathematics than it is applied English. Engineering students are expected to read and understand the content, drive conclusions and suggest solutions as part of their education. After all, "the four-year degree is not to provide industrial training for technicians" (Moran, 2016). Nonetheless, content-based classes, where students are expected to learn skills including reading fact-based texts, participating in discussions, and writing reflective pieces about the content are slim, and generally in the freshmen year of the progression, where students become disenchanted and drop out before they even get a chance to take heavy math and science oriented engineering courses (Bernold, 2005). 
When faculty are teaching content based classes, it is imperative that they rely on the Chickering and Gamson's (1987) seven principles for good practice in undergraduate education, specifically applying principle 3 to "encourage active learning."

The idea of active learning is synonymous with learner centered education, which benefits students by allowing them to self-regulate their own learning. Learner-centered education (LCE) is an approach that is increasingly being encouraged in higher education. This approach requires multiple teaching methods. Specifically, LCE emphasizes a variety of different types of methods that shifts the role of the instructors from providers of information to facilitators of student learning. Traditionally, instructors focus on what they do, and not on what the students learn. This emphasis on what instructors do often encourages students to become passive learners who do not take responsibility for their own learning. Educators call this traditional method, "instructorcentered teaching." In contrast, "learner-centered teaching" occurs when instructors focus on the learner and authentic problems rather than on the structured analysis of the curriculum content (Blumberg 2008, Gunderman et al. 2003). If teacher's primary focus is covering the content, students respond by memorizing the material with limited understanding. If the students are the ones doing hard and messy work, then the understanding is deeper (Weimer, 2013). Learning involves active construction of meaning by the learner, who construct meaning by combining what they currently know with the new information that they are acquiring. Meaningful learning can be facilitated by articulating explanations, whether to oneself, peers, or teachers in either written or oral form. Direct instruction could still be given after the students figured out what they need to know about the subject (Weimer, 2013).

Rogers (1993) describes a facilitative teacher as one who creates a learning environment rather than simply transmitting knowledge. To create this learning environment, one would expect students to expose themselves to the material prior to coming to class. Class preparedness, or reading prior to class turns into a constant struggle, especially with engineering students, who come to class with an expectation to work on problems but not to discuss them.

There is ample evidence that active learning techniques are consistently more effective than traditional lecturing and facilitated deeper learning, by creating a dominant pedagogical trend emphasizing active learning over passive learning (Yamane, 2006). Using active learning techniques in the classroom is also associated with building rapport with students, addressing students' misconceptions about course content, and working to increase student motivation. All of these practices have a positive impact on student learning, engagement, knowledge retention, and persistence.

Despite the large body of research supporting these effective teaching practices, lecturing still remains as common practice among engineering higher educators (Davis \& Minifie, 2013). According to the 2001 report released by the Department of Education, 87\% of engineering professors in the United States spent the entire class-time lecturing to a passive group of students who copied down material and never looked at it again. Engineering faculty identify several barriers to adopt active learning strategies. Such barriers include, but are not limited to, lack of familiarity with the practices, inadequate time to apply new teaching practices to their courses, and the possibility of student resistance (Anderson \& Finelli, 2014). Some educators who adopted learner-centered teaching reported lower student evaluations, and grumblings of students 
complaining that their professor made them do all the work instead of teaching them (Felder, 2011).

One of the biggest forms of resistance coming from my engineering students concerns reading the textbook. As Bernold (2007) pointed out, studying in college by its nature could be considered a skilled profession. One of the most important skills needed by the students is "reading to learn." According to the U.S. Department of Education, the reading assessment of 18,700 high school seniors in 2015 showed that students had an average score of 287 on the NAEP 0-500 reading scale, which showed no significant change from 2013, but was lower than the earliest assessment in 1992 with a score of 292. For a student to be considered proficient in reading, they need to achieve 302 on the scale. Students performing at or above the Proficient level on NAEP assessments demonstrate solid academic performance and competency over challenging subject matter. In 2015, 37\% of twelfth-grade students performed at or above Proficient on the reading assessment. Only $6 \%$ of twelfth-grade students performed at the Advanced level (minimum score of 346). These students are considered likely to have the skills to "Evaluate and compare arguments in two texts to support opinion about effectiveness" and "Integrate and interpret ideas to determine theme" and "Support evaluation of effectiveness of expository text with specific reference" (US Department of Education, NAEP Report Card, 2015).

Northern Arizona University does not have any additional admission requirements for acceptance in to the Engineering College other than general college admittance requirements. The average reading for the region where the majority of our students are from is 283. At this reading level, recognizing detail related to the purpose of a document and recalling it is difficult to achieve by an average student. Twelfth grade is an important transitional year that shows the readiness of students for college level course-work without remediation. "A series of studies conducted since 2008 indicate that students scoring at or above 302 on the NAEP reading scale are likely to possess the knowledge, skills, and abilities in reading that would make them academically prepared for college" (US Department of Education, NAEP, 2015).

Although a great deal of lifelong learning depends on reading, many students prefer getting their knowledge from other media (Nilson, 2013). United States reading assessments, conducted in 2015 revealed that number of pages read in school and for homework in $12^{\text {th }}$ Grade were as follows: 5 pages or fewer $(38 \%)$; 6 -10 pages $(22 \%)$; $11-15$ pages $(13 \%)$; $16-20$ pages $(10 \%)$ and more than 20 pages (17\%) (US Department of Education, NAEP, 2015).

Literature suggests many strategies that could be implemented to encourage students to complete their reading. An important aspect of reading is not just to complete it, but to go beyond and to be able to recall and understand the meaning of the text. Surprisingly, Roediger and Karpicke (2006) noted that reading fact-based material over-and-over resulted in substantially lower recall. Therefore, it is very important for students to understand how they learn from reading the text and to self-regulate in terms of quantity and quality of their reading.

In Fall 2015, an in-class activity called the "Mind Dump" was adapted for the class. Students were given 4 minutes and 33 seconds (Whitman, 2015) to write down all they can remember individually about the readings assigned for that week. The incentive for doing a good job on the Mind Dump is that the instructor returns these summaries to students for use during subsequent exams, by 
making their exam partly open notes. The goal is not only to get them to read the material prior to class but also to accrue learning in the process of careful reading and repeated retrieval, first in preparation for the writing of Mind Dump, then while actually doing it in the class (Nilson, 2013).

Mid-semester student feedback in the first semester (Group1) included the following. Students who Strongly Disagreed or Disagreed with the statement "Mind Dumps make me complete my readings" wrote "I don't understand what I am reading in the first place." or, "I can never remember what I read." Other comments for this same category involved "I never use mind dumps on my tests." “They don't look great, and they are not helpful to me during tests." These comments might be indicative of the low reading levels of some students in the class (US Department of Education, NAEP, 2015). Students who Strongly Agreed or Agreed with the statement wrote: "I know I will get them back before the exams." "Easy way to give myself an advantage on the tests." "Otherwise I'd procrastinate. The fact that I need to write something on the paper makes me feel "pressure" and that is why I read it." And, "I can prove to myself that I understand the reading."

However, a few student comments, mostly neutral about the statement, included significant suggestions for a format change. "Most confusing thing for me is the terms. I have never learned anything like this before so I am constantly behind in trying to be above the average in the class." "It is hard to get some of the vocab." "I would like a list of the words you want us to understand and know the definition." And, "they [Mind Dumps] are not graded they don't affect my grade."

In the second semester the class was taught by implementing the guided reading questions including a list of the vocabulary for Group 2. Mind Dumps were implemented the same way. Some student comments included "very helpful. I don't use my mind dumps on the test but that is because I know what I wrote, I remembered it because I completed my reading." and another student added "The benefits [are] in the long run for remembering the reading. It encourages me to do the reading and be ready for Mind Dumps." Although some students were able to see the point behind Mind Dumps, observations showed that still only $1 / 3$ of the class was Agreeing/Strongly Agreeing with "Mind Dumps make me complete my readings." A student comment was interesting to note "They are not graded, don't affect my overall grade." Prepared students would allow the instructor to use the in-class time to focus on learning activities to provide opportunities for critical thinking and deep learning. Student preparation before the class can happen, but it takes both sides and requires a different course design (Gillette \& David \& Gillette, 2012).

With these in mind, for the following semester (Group 3), the prior guided reading questions were turned into CPAs with the requirement that students provide their answers by handwriting to the guided reading questions and the vocabulary. They were expected to make a copy, and bring both copies to class, turn the original in, and keep a copy to take notes on during the lecture covering those topics. Gillette and Gillette suggest using the interactive model, which uses CPAs and definitional grading system. Students are expected to show good faith effort on CPAs, and need to get over $90 \%$ on the pass-fail work (CPAs) to get an A in the course (Gillette \& David \& Gillette, 2012). The changes implemented into the syllabus for Group 3 stated "at least $80 \%$ of the CPAs need to be completed to receive $13.5 \%$ of the overall grade in the course total." 
CPAs have been implemented by many educators in pursuit of going beyond lecturing (Yamane, 2006; Davis and Minifie, 2013). To the best of our knowledge, this is the first study investigating the effect of the CPAs in an introductory engineering class.

\section{Method:}

The sample consisted of three consecutive cohorts of students, Fall 2015 (N1=78), Spring 2016 $(\mathrm{N} 2=75)$ and Fall 2016 (N3=94), enrolled in 16 week Introduction to Environmental Engineering course. In order to assess the effectiveness of the pedagogical strategy adopted, the team crafted the following specific research questions:

RQ1: Which pedagogical strategy was the most effective one in getting students to read the material prior to the class?

RQ2: Are there any differences between the groups in engagement and student learning?

RQ3: What are the roles of engagement and reading in student learning across the groups? (To what extent reading and engagement predicted self-reported learning.)

Data collected for this study include researcher notes from the observations, responses to an inclass questionnaire that took place mid-semester of each semester the class was taught, and student opinion survey responses obtained at the end of the semester. Students were informed that the midsemester questionnaire is anonymous, and should take about 10 minutes to complete. Students responded to multiple items pertaining to their engagement, reading, and learning in the class, which were rated on 5-point Likert scale (Strongly Agree (5), Agree (4), Neutral (3), Disagree (2), and Strongly Disagree (1)).

Engagement was assessed with two items, E1 and E2 (Table 1). The mean of the two items was used to create the engagement composite score. Reading was assessed with two items as well, R1 and $\mathrm{R} 2$. The mean of the items was relied on for the composite reading score.

Table 1: Survey Questions for Engagement, Reading and Learning

\begin{tabular}{|l|l|}
\hline Dependent & Survey Item \\
\hline Engagement & E1. I am engaged in class always \\
\hline & E2. Overall, I am satisfied with my engagement in this class \\
\hline Reading & R1. I do my readings prior to the class \\
\hline & $\begin{array}{l}\text { R2. Mind Dumps or CPAs (stated the current technique for that semester) make } \\
\text { me complete my readings }\end{array}$ \\
\hline Learning & L1. I am learning something new in every class \\
\hline & L2. I am not learning in this class \\
\hline & L3. Overall, I am satisfied with my learning in this class. \\
\hline
\end{tabular}


Finally, three items were used to assess overall learning (L1 through L3 in Table 1). After reverse coding the second item (L2), the mean of the three items was used to create the composite score for this variable.

\section{Results:}

The means, standard deviations and correlations amongst the study variables across the groups are reported in Table 1. The first two research questions aimed to examine whether there were significant differences between the groups on reading, engagement, and learning. An analysis of variance (ANOVA) was computed for each independent variable to address these research questions. The ANOVAs for engagement $(\mathrm{F}(2,214)=1.93, \mathrm{p}=.15)$ and learning $(\mathrm{F}(2,214)=$ $.10, \mathrm{p}=.90)$ were not significant; indicating that the three groups had similar scores on these variables. The ANOVA for reading, however, was significant $(\mathrm{F}(2,214)=15.36, \mathrm{p}=.00)$. Posthoc comparisons using the Tukey HSD test indicated that the mean score for GROUP $3(\mathrm{M}=3.90$, $\mathrm{SD}=.74)$ was significantly different than Group $1(\mathrm{M}=3.27, \mathrm{SD}=.80)$ and Group $2(\mathrm{M}=3.22$, $\mathrm{SD}=.95)$, both significant at $\mathrm{p}<.01$. The mean scores for reading was not significantly different between Group 1 and Group 2. These analyses suggest that students read significantly more in Group 3, while there were not any differences between the groups on engagement and learning.

The correlations between the study variables across the groups were examined next. As reported in Table 2, the three variables were related to each other to varying degrees in each group with the only exception being the non-significant correlation between reading and engagement in Group 3. Also, the association of reading with learning in Group 2 was marginally significant $(p=.06)$.

Table 2: Means, Standard Deviations, and Correlations amongst the Study Variables across the Groups

\begin{tabular}{|c|c|c|c|c|c|c|}
\hline Group & & 1. & 2. & 3. & $M$ & $S D$ \\
\hline \multirow{3}{*}{1} & 1. Reading & - & & & 3.27 & .80 \\
\hline & 2. Engagement & $.40 *$ & - & & 3.65 & .93 \\
\hline & 3. Learning & $.41 *$ & $.55^{*}$ & - & 4.19 & .54 \\
\hline \multirow{3}{*}{2} & 1. Reading & - & & & 3.22 & .95 \\
\hline & 2. Engagement & $.37 *$ & - & & 3.86 & .73 \\
\hline & 3. Learning & $.22 \dagger$ & $.34^{*}$ & - & 4.21 & .56 \\
\hline \multirow{3}{*}{3} & 1. Reading & - & & & 3.90 & .74 \\
\hline & 2. Engagement & .13 & - & & 3.59 & .93 \\
\hline & 3. Learning & $.43 *$ & $.42 *$ & - & 4.22 & .64 \\
\hline
\end{tabular}

Note. $\dagger \mathrm{p}<.10$. $* p<.01$. 
Table 3: Hierarchical multiple regressions: Engagement and Reading as predictors of Learning across the groups

\begin{tabular}{|c|c|c|c|c|c|}
\hline Group & $\begin{array}{l}\text { Criterion/predictors } \\
\text { entered by step }\end{array}$ & $\beta 1$ & $\beta 2$ & $\mathrm{R}^{2}$ & $\Delta \mathrm{R}^{2}$ \\
\hline \multirow[t]{5}{*}{1} & Learning & \multirow{5}{*}{$.55^{* *}$} & & \multirow{3}{*}{.30} & \multirow{5}{*}{.04} \\
\hline & Step 1 & & & & \\
\hline & Engagement & & $.45^{* *}$ & & \\
\hline & Step 2 & & & .34 & \\
\hline & Reading & & $.23^{*}$ & & \\
\hline \multirow[t]{5}{*}{2} & Learning & \multirow{5}{*}{$.34 * *$} & & \multirow{3}{*}{.11} & \multirow{5}{*}{.02} \\
\hline & Step 1 & & & & \\
\hline & Engagement & & $.30 *$ & & \\
\hline & Step 2 & & & .13 & \\
\hline & Reading & & .11 & & \\
\hline \multirow[t]{5}{*}{3} & Learning & \multirow{5}{*}{$.42 * *$} & & \multirow{3}{*}{.17} & \multirow{5}{*}{.15} \\
\hline & Step 1 & & & & \\
\hline & Engagement & & $.36^{* *}$ & & \\
\hline & Step 2 & & & .32 & \\
\hline & Reading & & $.38^{* *}$ & & \\
\hline
\end{tabular}

Notes. $\beta 1, \beta 2=$ standardized beta coefficients for Steps 1, 2 .

$* p<.05, * * p<.01$

Next, we examined the extent to which reading and engagement predicted self-reported learning which addressed our third research question. In doing so, we focused on whether reading the course material made any difference in learning above and beyond engagement. Accordingly, we computed three regressions in which the first step included engagement, and reading was entered in the second step. The results are presented in Table 3.

In every group, the first step including engagement was significant (Group 1: $F(1,71)=29.64, p$ $<.001$; Group 2: $F(1,71)=9.05, p<.001$; Group 3: $F(1,72)=14.74, p<.001)$ and explained $30 \%, 11 \%$, and $17 \%$ of the variance in learning across the groups, respectively (See Table 2 ). The second step including reading was also significant in every group (Group 1: $F(2,71)=17.97, p<$ .001 ; Group 2: $F(2,71)=4.94, p<.01$; Group 3: $F(2,72)=16.14, p<.001)$. Reading explained an additional $4 \%, 2 \%$, and $15 \%$ of the variance in learning above and beyond engagement across the groups, respectively. However, as seen in Table 2, although the second step was significant in Group 2, the beta coefficient for reading was not significant. These analyses showed that, with the exception of Group 2, reading made a difference in learning while controlling for engagement, while it had the biggest impact in Group 3. Collectively, the two variables explained between 13\% and $34 \%$ of the variance in learning. 


\section{Conclusion:}

Class Preparation Assignments (CPAs) were an effective technique to get students to read the material prior to class. Group 3 was reading the most among all the groups. Some student comments at the end of the semester for cohort 3 provided important insights about the utility of this approach: "One thing in which I greatly admired in this course was the CPA's. These are in my opinion invaluable and are what helped me do so well in the class. It is true that the CPA's do consume a lot of time. There are several reasons I think CPA's were so helpful and indispensable for me. The first of which is that it did take me a long to do so. Spending so much time over the chapters made it so that more of the information was stuck in my head and that I remembered more. Secondly, in order to answer the questions, I had to reread bits of the chapter; in so rereading, I felt I was very familiar in the end with the material. In short, doing the CPA's forced me to become intimate with the content of the chapter, and in so doing helped me succeed in the class. I would say that anyone who truly committed to doing the CPA's earnestly could not help but do well in the class." and "I like how CPA's were done, because it encouraged me to read the textbook more in-depth than I normally would.”

Analyses also showed that reading in Group 3 made the biggest contribution to student learning compared to other groups. Adding a partially definitional grading system seemed to increase the students' motivation to complete reading, and do preparatory work prior to the class. CPAs with grading provide a strong preparation for active learning in class.

Engagement in large is defined as student actions and pedagogic presentations. Researchers believe that engagement can be measured by observing a student's level of participation in their academics. Engaging pedagogy appeals to students and should include peer to peer activities, selfreflection, active learning, and research (Heller et al 2010). Interestingly, the groups did not differ from each other on engagement and learning. However, although engagement was a reliable predictor of leaning in every group, reading the material made the biggest contribution to learning in Group 3. That is, CPAs made a difference in student learning by enhancing their reading.

\section{References:}

- U.S. Department of Education, Institute of Education Sciences, National Center for Education Statistics, National Assessment of Educational Progress (NAEP), 2015 Reading Assessment)

- Whitman, G. (2015) Web post: 4'33" (Four Minutes and Thirty-Three Seconds): What Our Brains Need, www.Edutopia.org retrieved on Dec 14, 2016.

- Moran, S. (2016) Prism ASEE publications Opinion p.60 Link: https://www.asee.org/documents/publications/prism/2016-ASEE-PRISM-Magazine-25$\underline{\text { 6.pdf }}$

- U.S. Department of Education (2001) The context of postsecondary education. The Condition of Education, NCES 2001072, National Center for Education Statistics, U.S. Department of Education, Washington, D.C., 74-84.

- Bernold, L.E. (2005) Paradigm Shift in Construction Education is Vital for the Future of Our Profession, DOI: 10.1061/(ASCE)0733-9364(2005)131:5(533) 
- Chickering AW, Gamson ZF. Seven principles for good practice in undergraduate education. Biochem Educ. 1987: 17(3):140-141. doi:10.1016/0307-4412(89)90094-0.

- Blumberg, P. (2008) Developing Learner-Centered Teachers: A Practical Guide for Faculty http://www.usciences.edu/teaching/LearnerCentered/Blumberg_Developing_Learner_Centered_Teaching.pdf

- Gunderman, R.B. et al. (2003)Learner Centered Education, Radiology. http://pubs.rsna.org/doi/full/10.1148/radiol.2271021124

- Weimer, M. (2013). Learner-Centered Teaching (second). San Francisco, CA: Jossey-Bass Publishers.

- Rogers, C. R. (1993). The interpersonal relationship in the facilitation of learning. In M. Thorpe, R. Edwards, \& A. Hanson (Eds.), Culture and processes of adult learning (pp. 228242). London: Routledge.

- Yamane, D. (2006) Course Preparation Assignments: A Strategy for Creating DiscussionBased Courses, Teaching Sociology, Vol. 34, No. 3 (Jul., 2006), pp. 236-248

- Davis, K. and Minifie, J.R. (2013) Ensuring Gen Y students come prepared for Class; then leveraging active learning techniques to most effectively engage them. American Journal of Business and Management, (2):1, 13-19.

- Anderson, O. S., \& Finelli, C. (2014, June), A Faculty Learning Community to Improve Teaching Practices in Large Engineering Courses: Lasting Impacts Paper presented at 2014 ASEE Annual Conference \& Exposition, Indianapolis, Indiana. https://peer.asee.org/19938: Link https://peer.asee.org/a-faculty-learning-community-to-improve-teaching-practices-inlarge-engineering-courses-lasting-impacts

- Felder, R.M. (2011) HANG IN THERE! Dealing with Student Resistance to LearnerCentered Teaching, Chemical Engineering Education, 45(2), 131-132

- Bernold, L.E. (2007) Preparedness of Engineering Freshman to Inquiry-Based Learning, Journal of Professional Issues in Engineering Education and Practice, ASCE, 133(2): 99-106.

- Roediger, H. L.; Karpicke, J. D. (2006). Test- Enhanced Learning: Taking Memory Tests Improves Long-terms Retention . Psychological Science 17 (3): 249-255.

- Nilson, L. 2013, Creating Self-regulated Learners: Strategies to Strengthen Students' SelfAwareness and Learning Skills (Stylus Publishing, Virginia)

- Gillette, L., Davis, K.S., \& Gillette, J. R. (2012). Active Learning Teaching Strategies to Promote Student Learning and Create Intellectual Excitement in the Classroom. ACBSP 2012 Annual Conference. Baltimore, MD.

- Heller, R.S.; Beil, C.; Dam, K.; Haerum, B. (2010) Student and Faculty Perceptions of Engagement in Engineering, Journal of Engineering Education, July, pp.253 -261

Appendices:

I. Student sample of Mind Dump

II. Student Sample CPA (with Questions) for Water Treatment Chapter 
mind dumps

$03 / 07 / 2016$

In the given slides we studied about different type

bf water treatment. It include three main types

primary secondary and tertiary water treatment. 


\section{CPA Chapter 9}

1. Define the following terms:

a. Unit operation: an operation used in the treatment of water in which change is brought about by means of or through application of physical forces.

b. Unit Process: water treatment technologies that are biological or chemical

c. Water Hardhess: the amount of dissolved calcium and magnesium in the water

d. Coagulation: adding chemicals such as alum, which produces positive charges to neutralize the negative charges on the particles, to water

e. Flocculation; the process by which fine particulates are caused to clump together into a floc. The floc may then float to the top of the liquid (creaming), settle to the bottom of the liquid (sedimentation), or be readily filtered from the liquid

f. Sedimentation/Settling: sedimentation is a physical water treatment process using gravity to remove suspended solids from water settling basins are pondis constructed for the purpose of removing entrained solids by sedimentation

g. Filtration a unit operation that involves the separation of nonsettleable solids from water or wastewater by passing the water through a porous medium

h. Granular Media: the process for removal of suspended solids by passage of water through a porous medium

i. Disinfection: a unit process in which a chemical is added to the treated water to oxidize residval organics and pathogens.

$j$ Sterilization: the objective is to destroy all microorganisms.

K. Disinfectant: the disinfectant selected should act as a powerful oxidizing agent adition to providing residual in the water distribution system to eliminate regiowith of pathogens

1. Coagulant Aid: includes acids and hases that may be added to the water to maintain a specific pH 
m. Coagulant: aluminum and iron salts are the major tupes of coagulants used in water treatment, primarily aluminum sulfate, ferrous suifate, ferric chloride, ferric sulfate, and sodium aluminate

n. Floc: a flocculant mass formed in a fluid through presipitation or aggregation of suspended particles.

o. Colloidal Particie: particles that are extremely small and have negligible mass and large surface area perc unit volume. They cannot be removed by sedimentation and acquire a negative ourface charge p. Water Softening: a unit process involving the addition of chemicals to water for the removal of ions that cause hardness

Q. Chemical Precipitation: the primary meanc of removing hardness from water through the addition of lime (caO) and seda ash ( $\mathrm{Na}_{2} \mathrm{Cl}$

r. Headloss: the losses in the pipes and networks aerovic or hydravlic designates the irreversible loss of pressure energy, that undergoes a liquid or a gas as it passes through a condvit, or another fitting of fluid network

S. Clogging: to hinder or obstruct with thick or sticky watter

1. Filler Backenash: pumping water backwards through the filters media, sometimes including intermittent use of compressed air during the process. It is a form of preventive maintenance so that the filter media can be used

U. Human Enteric Pathogens: rod-shaped Gram-negative bacteria; most occur normally or pathogenically in intestines of humans and otiner animal V. Slean Water Act (CWA): the primary federal law in the U.S. governing water pollution; it's objective is to restore and maintain the chemical, physical, and bislogical integrity of the hationis waters by prevent point and nonpoint pollution sources, providing assistance to publicly ouned treatment warks for the improvement o wastewater treatment, and maintaining the integrity of wettands W. THM: types of disinfestanis used that also affects the production of potential or suspected carcinegens

X. Sare Orinking watec standards: the principal federal law in the U.S. intended to ensure safe drinking water for the public 
2. How do we select the type of water treatment technologies we use? There are three primary considerations for selecting the appropriate treatment technology: (1) the water quality of the source, (2) the required and /or desired quality of the treated water, (3) the emerging contaminants and the types of technologies that will be required for removing them from water.

3. What does the degree of water treatment depend on?

The degree of water treatment depends on the source and lucation of where the water is coming from.

4. What does a conventional surface water treatment plant flow diagram look like?
Raw Water
$\downarrow$
Bar Rack
Sedimentation $\rightarrow \rightarrow$ siudge
$k$ oxidant/disinfectant

Screens $\downarrow$

Flow Measurement

- - pH adjustment

- oxidant/disinfectant

\&-coagulant

Mixing

5. How does coagulation / flocculation work?

Filtration $\rightarrow$ Backwash to washwater vecovery pand 1 - oxidant/disinfectant and flounide

Clear Woll

$\downarrow$

High-Service Pumps

Foxidant/disinfectant

to distribution system

Coagulation is a unit process consisting of the addition and mixing of a chemical reagent to destabilize colloidal and tine solids suspended in water. Flocculation invalves slow stirning or gentle agitation to promote agglomeration of the destabilized particles formed during coagulation, so that heavy, rapia-setiling flocs are formed.

b. What can be veed as a coagulant?

Aluminum and iren salts are the major types of coagulants used in water treatment, primarily aluminum sulfate, ferrous sulfate, ferric chionide, ferric sulfate, and sodium aluminate. 
7. What are coagulant aids? What are they used for? How do we know how much to add?

coagulant aids include acids and bases that may be added to water to maintain a specific pH. The quantily of coagulant that must be added to a partirular type of water must be determined through experimentation.

8. What causes water to be hard? Water hardness is caused by polyvalent metallic cations, principally calcium $\left(\mathrm{Ca}^{2+}\right)$ and that contribute to hardness include iron $\left(\mathrm{Fe}^{2+}\right)$, manganese $\left(\mathrm{Mn}^{2+}\right)$, and strontiven $\left(S r^{2+}\right)$.

9. What types of problems are associated with hard water? Hardness isn't related to any health issue but is undesirable because. it produces scale in water heaters and pipes and increases consumption of soap and detergent.

10. What is water softening? How is it achieved? Water softening is a unit process involving the addition of chemicals to water for the removal of ions that cause hardness. It is achieved through chernical precipiration, which adds lime ( $\mathrm{CaO})$ and soda ash $\left(\mathrm{Na}_{2} \mathrm{CO}_{3}\right)$ to the water treatment plan.

II. How does sedimentation reactor work?

Sedimentation is a unit operation involving solids-liquid separation by gravitational settling to remove suspended solids. In water treatment, two types of settling are encountered. Type I - fres or discrete settling, and Type II-flocculent setting.

12. How does filtration work?

Filtration is a unit operation that involves the separation of nonsettleable solids from water or lwastewater by passing the water throvgh a porous medium.

13. Why do filters need is be backwashed?

Filters need th be bockwashed in order to remove the particles and turbidity that have accumulated. 
14. What are the categories of human enteric pathogens?

The four major categories of human enteric pathogens are bacievia, viruses, protozoa, and helminths.

15. What are the common disinfectants used for water treatment? Which one is used mast offen?

some common disinfectants used for water treatment are chlorine, sodium hypochlorite, chlorine dioxide, chloramines, hydrogen peroxide, copper/silver ionisation, bromine, ozone, and UV Radiation. The most commonly used is chlorine.

16. What are the pros and cons of alternative water disinfectants? A major advantage to using ozone is that THMS are not formed. A disadvantage to chlorine dioxide is that it may reduce to chlorate, a potential carcinagen. Two disadvantages to UV radiation is that (1) there is no residual, so chlorine or alternative disinfectants must be added, and (2) the quart2 sleeves must be cleaned periodically.

17. How do water disinfectants work, what are the mechanisms? The effectiveness of the disinfection process is determined by both the concentration and contact time. Several mechanisms incivde (1) Destroying the cell walls, (2) Altering cell permeability, (3) penetrating the cell, causing reactions with enzymes and protoplasm, and (4) Damaging the cell's DNA and RNA.

18. What is chlorine residval? How much chlorine residval is provided at the furthest tap in the system?

The two types of chlorine rssidval is free available chlonine residval and combined chlorine residval. The amount of chlorine residual provided depends on how much chlsrine was added.

19. What are disinfection by products (DBPS)? How do they form? $D B P S$ are chenical, organic, and inorganic substances that can form during a reaction of a disinfectant with naturally present organic matter in the water. 
20. Watch the videos. Summarize your understanding in one sentence for each videa.

BJWSA Water Treatment Doncess:

Water is sent through many processes and stens to ensure it's quality before ine ever get to drink it.

Drinking Water Ireatinenat Dlant:

Alternative disinfectant methods involue move steps to the water treatment process but the water quality ends up being better. Flocculation:

Flocculation is crucial to the water treatment process because it forces the coiloids to clump together and sink, which leaves behind clear laiater. How does Flocellation/Eloatation Work?

Water needs flocculation in order to become clearer, however the sludige leftover has to be dealt with too. 